\title{
Effect of Gratitude Training Program on Dental Hygiene Students' Gratitude Disposition, Self-Esteem, and Happiness
}

\author{
So-Young Lee ${ }^{\dagger}$ \\ Department of Dental Hygiene, Taegu Science University, Daegu 41453, Korea
}

The purpose of this study was to examine whether a gratitude training program for preservice dental hygienists affects their gratitude disposition, self-esteem, and happiness. Dental hygiene students were recruited from a college in D and administered a pretest. The 76 selected participants were primarily those who had never written a gratitude journal. Participants were then randomly divided into an experimental group and a control group. Three participants failed to complete the program, leaving 73 subjects in the final analysis. Data were analyzed using the $\chi^{2}$ test, independent sample t-test, and analysis of covariance. The mean gratitude disposition score improved from $31.11 \pm 5.55$ in the pretest to $34.41 \pm 4.38$ in the posttest in the experimental group and from $31.44 \pm 4.41$ to $32.06 \pm 4.63$ in the control group. The mean self-esteem score improved from $31.22 \pm 4.03$ to $33.16 \pm 3.44$ in the experimental group and from $30.53 \pm 4.42$ to $30.97 \pm 3.80$ in the control group. The mean happiness score improved from $19.54 \pm 2.64$ to $21.78 \pm 2.43$ in the experimental group and from $19.64 \pm 3.32$ to $20.08 \pm 2.91$ in the control group. All of the participants improved their gratitude disposition, self-esteem, and happiness scores while participating in the gratitude training program, and it is expected that if such positive emotions can be sustained, they will naturally acquire the basic requirements of dental hygienists and build a better vocational consciousness and a higher sense of duty, as well as have a further positive effect on the quality of dental medical service. Further studies should be conducted to propose a concrete plan to expand and operate this gratitude training program more effectively.

Key Words: Happiness, Gratitude disposition, Gratitude training program, Self-esteem

\section{Introduction}

As rapid advancements in medical technology have improved standards of living and increased average life expectancy, people's interest in health has grown. Along with the growing interest in overall health, interest and awareness regarding the importance of sound oral health have also increased, resulting in a growing demand for quality dental healthcare ${ }^{1)}$. Consumer satisfaction is a key factor determining the quality of care when it comes to dental health services ${ }^{2}$, and the quality of dental health services is a critical element of competitiveness in the healthcare market ${ }^{3)}$.

Adequate access to dental health services and regular dental check-ups can reduce the risk of oral disease, preserve the function of teeth and gums, and improve the overall quality of life ${ }^{4)}$, and patients have high expectations for the dental health services they receive. To evaluate the quality of healthcare services, it is imperative to evaluate its functional value as perceived by the patients $^{5,6}$. The same is true for dental health services in that not only the clinical outcomes but also patient satisfaction are important factors measuring the quality of services $^{7}$. Dental health services are consumed by the patient as they are being produced by the provider, a characteristic that makes human factors all the more important in determining quality ${ }^{8)}$. Alongside dentists, dental hygienists are primary providers of oral healthcare 
services, and they are not only asked to assume the role of healthcare professionals equipped with professional knowledge and medical expertise but also to provide quality healthcare ${ }^{9)}$. Healthcare quality can be measured via patient satisfaction surveys ${ }^{10)}$. Patient satisfaction and preference tend to increase as dental hygienists' awareness increases $^{7)}$, and the interaction between healthcare workers and patients influence the outcomes of healthcare services rendered ${ }^{11)}$. A positive state of mind is requisite for all who provide client services and is associated with the quality of service provided ${ }^{12,13}$. Dental hygienists provide dental health services to patients. To improve the quality of care dental hygienists provide, it is important to improve the quality of life among these professionals. On this note, we need to turn our attention to positive psychology, wherein individuals' positive and subjective experiences/attributes, as well as institutional tools supporting them, are examined ${ }^{14,15)}$. Positive psychology is a scientific study of various positive emotional states experienced by individuals, of their positive traits and strengths, and of positive institutions and policies supporting the happiness and self-actualization of the society's constituents ${ }^{16)}$. In examining these three aspects, positive psychology focuses primarily on the two themes of gratitude and happiness ${ }^{14}$. Gratitude is an emotion expressing appreciation and joy for other people, objects, or nature ${ }^{17)}$, which helps us to perceive a negative event under a more positive light ${ }^{18)}$. Gratitude disposition is the conceptualization of emotional characteristics predisposed towards gratitude ${ }^{14)}$ and refers to a grateful and positive emotional state in which an individual perceives generosity and good will of another person through his/her positive emotional experience ${ }^{19,20)}$. Experiencing gratitude is important for one's personality development and social life $^{21)}$. Individuals with a stronger gratitude disposition tend to have higher self-appraisal and self-esteem as a result of viewing their circumstances as a blessing ${ }^{17-19}$. Self-esteem refers to the degree to which an individual values him/herself, however positively or negatively, based on the understanding of self as an independent entity $^{22)}$. As such, self-esteem is associated with the individual's positive attitude toward life and psychological health ${ }^{14)}$ and highly associated with subjective happiness ${ }^{23,24)}$. Positive attitude is a requisite trait for dental hygienists as dental health professionals. The present study examines the effect of a gratitude training program on dental hygienists' gratitude disposition, self-esteem, and happiness.

\section{Materials and Methods}

\section{Study subjects}

Upon obtaining Kosin University's Institutional Review Board approval (IRB no. 1040549-150407-SB-0023-01), dental hygiene students attending school in Daegu Metropolitan City were recruited between March 2 and June 30, 2016. Candidates were briefed on the gratitude training program's purpose and procedure, and those who were willing to participate were administered a pretest. Candidates who had never kept a gratitude journal were primarily selected for the study and were then randomly assigned into the experimental group or the control group. After excluding 3 subjects who failed to complete the program, 73 subjects ( 37 in the experimental group, 36 in the control group) were included in the final analysis.

\section{Study procedure}

\section{1) Subject selection and pretest}

A pretest was administered between March 2 and 9, 2016, to the students who agreed to participate in the program. The pretest assessed gratitude disposition, self-esteem, happiness, and previous history of participation in a gratitude training program among the dental hygienists in training. The primary subjects were selected based on the results of the pretest, and selected subjects were then randomly assigned into the experimental group or the control group.

\section{2) The program}

Each subject kept a gratitude journal from March 9 to May 31, 2016, in which they wrote at least once daily (at the end of the day before going to bed) or as many time as needed in a day. Although no limit was imposed on the length or content of each daily entry, subjects had to seek out and record at least one specific thing they felt grateful 
for during the course of a given day. They were encouraged to not repeat specific objects/recipients or details of gratitude in order to promote diversity of content, but an individual's decisions regarding what to write in the journal was respected as much as possible. In accordance with the principles of nondisclosure and confidentiality, the content of the gratitude journal was not to be used for any purpose other than that of the study.

\section{3) Posttest}

A posttest using the same instruments and procedures as in the pretest was administered to the experimental group and the control group to measure the effects of the gratitude training program on gratitude disposition, self-esteem, and happiness among the participating dental hygienists in training.

\section{Study instruments}

\section{1) Gratitude disposition}

To measure gratitude disposition, the K-GQ-6, which is the Gratitude Questionnaire (GQ-6) developed by McCullough et al. ${ }^{19)}$ and translated into the Korean language by Kwon et al. ${ }^{25)}$, was used. The scale consists of 6 questionnaire items, 4 of which are positive items and 2 of which are reverse-scored. Each item is scored on a 7-point Likert scale (minimum: 1 point, maximum: 7 points), with a higher score reflecting a stronger disposition toward gratitude.

\section{2) Self-esteem}

To measure self-esteem, Rosenberg's Self-Esteem Scale $^{22)}$ translated by Jeon ${ }^{26)}$ into the Korean language, was used. The scale consists of 10 items, 5 of which are positive items and the remaining 5, reverse-scored. Each item is scored on a 4 point-Likert scale (minimum: 1 point, maximum: 4 points), with a higher score reflecting greater self-esteem.

\section{3) Subjective happiness}

To measure subjective happiness, Lyubomirsky and Lepper's Subjective Happiness Scale ${ }^{27)}$ translated by Seligman and $\mathrm{Kim}^{28)}$ into the Korean language, was used.
The scale consists of 4 items, each of which is scored on a 7-point Likert scale (minimum: 1 point, maximum: 7 points), with a higher score reflecting greater subjective happiness.

\section{Data analysis}

A $\chi^{2}$ test was performed for homogeneity analysis of the general characteristics of the experimental and control groups. Pre- and posttests were analyzed and reported as means and standard deviations. To identify the process of change and to compare group differences, an analysis of covariance was performed with pretest scores as a covariate, depending on the pretest scores' homogeneity test results (independent t-test). SAS ver. 9.4 (SAS Institute, Cary, NC, USA) was used for data analysis, and the significance level was set at $\mathrm{p}<0.05$.

\section{Results}

\section{Homogeneity testing for general characteristics}

Regarding religion, $27.0 \%$ of the experimental group was religious, and $73.0 \%$ were nonreligious. In the control group, the figures were $38.9 \%$ and $61.1 \%$, respectively. Regarding age, subjects aged 18 years and younger accounted for $64.9 \%$ and subjects aged 19 years and older accounted for $35.1 \%$ of the experimental group. In the control group, the figures were $77.8 \%$ and $22.2 \%$, respectively. Regarding motivation for participation in the program, $67.6 \%$ of the experimental group showed an intrinsic motivation, and $32.4 \%$ showed an extrinsic motivation. In the control group, the figures were $75.0 \%$ and $25.0 \%$, respectively. Regarding subjective health, $67.6 \%$ of the experimental group reported good subjective health, and $32.4 \%$ reported below average subjective health. In the control group, the figures were $80.6 \%$ and $19.4 \%$, respectively. Regarding interpersonal relationships, 75.7\% of the experimental group reported good interpersonal relationships, and $24.3 \%$ reported poorer than average interpersonal relationships. In the control group, the figures were $86.1 \%$ and $13.9 \%$, respectively. Regarding the degree of satisfaction with their choice of major, $70.3 \%$ of the experimental group reported they were satisfied, while $29.7 \%$ reported less than average satisfac- 
Table 1. Homogeneity for General Characteristics between Two Groups ( $n=73$ )

\begin{tabular}{|c|c|c|c|c|}
\hline Variable & Experimental group $(n=37)$ & Control group $(n=36)$ & $\chi^{2}$ & $\mathrm{p}$ \\
\hline Religion & & & 1.16 & 0.281 \\
\hline Yes & $10(27.0)$ & $14(38.9)$ & & \\
\hline No & $27(73.0)$ & $22(61.1)$ & & \\
\hline Age (y) & & & 1.48 & 0.223 \\
\hline$\leq 18$ & $24(64.9)$ & $28(77.8)$ & & \\
\hline$\geq 19$ & $13(35.1)$ & $8(22.2)$ & & \\
\hline Entering motivation & & & 0.49 & 0.483 \\
\hline Active motivation $^{\mathrm{a}}$ & $25(67.6)$ & $27(75.0)$ & & \\
\hline Passive motivation $^{\mathrm{b}}$ & $12(32.4)$ & $9(25.0)$ & & \\
\hline Subjective health condition & & & 1.60 & 0.206 \\
\hline Healthy & $25(67.6)$ & $29(80.6)$ & & \\
\hline Below average & $12(32.4)$ & $7(19.4)$ & & \\
\hline Interpersonal relationship & & & 1.28 & 0.258 \\
\hline Good & $28(75.7)$ & $31(86.1)$ & & \\
\hline Below average & $9(24.3)$ & $5(13.9)$ & & \\
\hline Major satisfaction & & & 0.01 & 0.939 \\
\hline Satisfaction & $26(70.3)$ & $25(69.4)$ & & \\
\hline Below average & $11(29.7)$ & $11(30.6)$ & & \\
\hline Economic status $^{\mathrm{c}}(10,000 \mathrm{KRW})$ & & & 6.69 & 0.035 \\
\hline High & $5(13.5)$ & $13(36.1)$ & & \\
\hline Average & $27(73.0)$ & $16(44.4)$ & & \\
\hline Low & $5(13.5)$ & 7 (19.4) & & \\
\hline
\end{tabular}

Values are presented as $\mathrm{n}(\%)$.

KRW: Korean won.

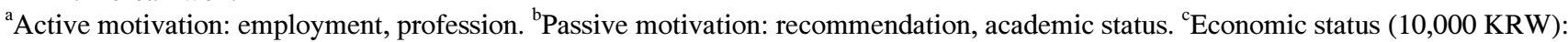
low, <199; average, $200 \sim 399$; high, $\geq 400$.

Table 2. Homogeneity for Dependent Variables between Two Groups

\begin{tabular}{lccc}
\hline \multicolumn{1}{c}{ Variable } & $\begin{array}{c}\text { Experimental } \\
\text { group }(\mathrm{n}=37)\end{array}$ & $\begin{array}{c}\text { Control group } \\
(\mathrm{n}=36)\end{array}$ & $\mathrm{p}$-value \\
\hline Gratitude disposition & $31.11 \pm 5.55$ & $31.44 \pm 4.41$ & 0.776 \\
Self-esteem & $31.22 \pm 4.03$ & $30.53 \pm 4.42$ & 0.489 \\
Happiness & $19.54 \pm 2.64$ & $19.64 \pm 3.32$ & 0.889 \\
\hline
\end{tabular}

Values are presented as mean \pm standard deviation.

tion. Regarding economic status, the majority $(73.0 \%)$ of the experimental group were classified as middle class, followed by upper class and lower class at $13.5 \%$ each. Similarly, in the control group, the majority $(44.4 \%)$ were classified as middle class, followed by upper class at $36.1 \%$ and lower class at $19.4 \%$ (Table 1 ).

\section{Homogeneity testing for dependent variables}

The experimental group's average gratitude disposition score was $31.11 \pm 5.55$ points, and the control group’s was
$31.44 \pm 4.41$ points, showing no significant group difference. Regarding self-esteem, the experimental group's average score was $31.22 \pm 4.03$ points, and the control group's was $30.53 \pm 4.42$ points, also showing no significant group difference. Regarding subjective happiness, the experimental group's average score was $19.54 \pm 2.64$ points, and the control group's was $19.64 \pm 3.32$ points, which also did not show a significant group difference (Table 2).

\section{Changes in gratitude disposition, self-esteem, and} subjective health following the training program

The average gratitude disposition score of the experimental group increased from $31.11 \pm 5.55$ points in the pretest to $34.41 \pm 4.38$ points in the posttest, and the improvement was significantly higher than that of the control group $(\mathrm{p}<0.001)$.

The average self-esteem score of the experimental group increased from $31.22 \pm 4.03$ points in the pretest to 
Table 3. Gratitude Disposition, Self-Esteem and Happiness Related Gratitude Training Program Changes

\begin{tabular}{lllcrrr}
\hline \multicolumn{1}{c}{ Variable } & \multicolumn{1}{c}{ Group } & Pretest & Posttest & Change (post-pre) & $\mathrm{t}$ & $\mathrm{p}$ \\
\hline Gratitude disposition & Experimental $(\mathrm{n}=37)$ & $31.11 \pm 5.55$ & $34.41 \pm 4.38$ & $3.30 \pm 4.36$ & 2.84 & $<0.001$ \\
& Control $(\mathrm{n}=36)$ & $31.44 \pm 4.41$ & $32.06 \pm 4.63$ & $0.61 \pm 4.46$ & 0.82 & 0.417 \\
Self-esteem & Experimental $(\mathrm{n}=37)$ & $31.22 \pm 4.03$ & $33.16 \pm 3.44$ & $1.95 \pm 2.09$ & 5.65 & $<0.001$ \\
& Control $(\mathrm{n}=36)$ & $30.53 \pm 4.42$ & $30.97 \pm 3.80$ & $0.44 \pm 4.22$ & 0.63 & 0.531 \\
Happiness & Experimental $(\mathrm{n}=37)$ & $19.54 \pm 2.64$ & $21.78 \pm 2.43$ & $2.24 \pm 1.94$ & 7.05 & $<0.001$ \\
& Control $(\mathrm{n}=36)$ & $19.64 \pm 3.32$ & $20.08 \pm 2.91$ & $0.44 \pm 2.01$ & 1.33 & 0.192 \\
\hline
\end{tabular}

Values are presented as mean \pm standard deviation.

$33.16 \pm 3.44$ points in the posttest, and the improvement was significantly higher than that of the control group $(\mathrm{p}$ $<0.001)$.

The average subjective happiness score of the experimental group increased from $19.54 \pm 2.64$ points in the pretest to $21.78 \pm 2.43$ points in the posttest, and the improvement was significantly higher than that of the control group $(\mathrm{p}<0.001)$ (Table 3$)$.

\section{Discussion}

The present study aimed to identify the effect of a gratitude training program on the gratitude disposition, self-esteem, and subjective happiness of dental hygienists in training. To this end, dental hygiene students attending school in Daegu Metropolitan City who were briefed on and agreed to the study's purpose and procedure were recruited and then administered a preliminary test. Those reporting that they had never kept a gratitude journal were selected as primary subjects for the analysis and were then randomly assigned into the experimental group and the control group. Following the conclusion of the 12-week training program, the two groups were tested again (posttest) while using the same scales and procedures used in the pretest.

The average gratitude disposition posttest scores of the experimental group increased significantly from the pretest scores, and the dental hygienists in training who completed the gratitude training program showed greater improvement in gratitude disposition than their counterparts who did not participate in the program. This result is consistent with Yang's study ${ }^{14)}$ involving early childhood educators in training, as well as Lee and Lee's study $^{29)}$ involving middle school students. It is thought that selecting individuals with no previous history of participation in gratitude training, confirming the definition and meaning of gratitude, and having the participants seek out/record in a daily journal the various events and objects/people in everyday life for which they are grateful contributed to improved gratitude disposition by helping them adopt and maintain a more positive outlook and emotional state. Individuals with a strong gratitude disposition had a greater level of life satisfaction as well as a greater tendency for positive traits such as extroversion, conscientiousness, and positive emotions. Conversely, negative traits such as a tendency for depression, anxiety, stress, and emotional sensitivity are less likely in these individuals ${ }^{19)}$. Furthermore, individuals who habitually experience gratitude have been found to engage in more pro-social behaviors and to behave morally while suppressing socially negative behaviors ${ }^{19)}$. A strong gratitude disposition in dental hygienists in training is thought to promote quality dental health services as it can strengthen the positive attitude in a group culture and contribute to improved patient-doctor relationships and increased satisfaction.

Posttest self-esteem scores of subjects in the experimental group who kept a gratitude journal increased significantly from the pretest scores, and dental hygienists in training who completed gratitude training had a greater improvement in self-esteem than their counterparts who did not participate in such training. This result is consistent with Yang's study ${ }^{14)}$ involving early childhood educators in training, as well as Lee and Lee's study ${ }^{29}$ involving middle school students. Writing in the gratitude journal everyday while consciously looking for something 
to be grateful for in everyday life is thought to have had a positive effect on the subjects' emotional state and attitude, resulting in increased self-worth. It has been reported that individuals who perceive a high level of gratitude for others ${ }^{19)}$ have improved self-esteem in interpersonal relationships and have increased self-worth. Similarly, higher self-esteem is associated with increased quality of life, happiness, positive perception of one's job, and job satisfaction ${ }^{30)}$. As such, a training program designed to encourage habitual practice of positive emotions and attitude is required.

Posttest happiness scores among subjects in the experimental group who kept a gratitude journal increased significantly from the pretest scores, and dental hygienists in training who completed gratitude training had a greater increase in subjective happiness than their counterparts who did not participate in such training. This result is consistent with Yang's study ${ }^{14)}$ involving early childhood educators in training, as well as Park and Kim's study ${ }^{31)}$ involving elementary school students. A sense of happiness refers to a subjective and positive emotional state resulting from accepting one's life according to the standards of one's own choosing ${ }^{32)}$. Seligman et al. ${ }^{33)}$ conducted happiness exercises as a positive psychology intervention, in which participants were asked to write and deliver gratitude letters for a week to those whom they had not previously been able to show appreciation for their kindness, record three positive things experienced during the course of a day for a week, and apply personal strengths in new ways for a week. Following the intervention, participants showed increased subjective happiness. Happiness increases with one's effort and continuous training, and gratitude training programs are thought to be highly correlated with increased happiness as they encourage conscious recognition of a diverse range of positive experiences in everyday life that would be overlooked otherwise, thus improving quality of life. Therefore, it is thought that such programs help dental hygienists in training to build a solid emotional basis upon which to build a successful professional career and function as robust and dedicated members of an organization. The present study found group differences according to participation in a gratitude training program, in which subjects who participated in the program were confirmed to have increased gratitude disposition, self-esteem, and subjective happiness.

Because the present study's subject selection was limited to dental hygiene students from one particular locale, generalization of its results requires caution. On this note, a follow-up study incorporating a more diverse group of subjects in terms of years in school or sex would be beneficial to see if the results may be replicated. Because variables such as personality type, behavioral characteristics, and psychological state were not incorporated in the present study, a follow-up study considering these and other variables is also thought to be needed. Furthermore, a reassessment at some later point following the conclusion of the gratitude training program would be helpful to track any changes in the measured variables and examine how well the program's positive effects are sustained over time. Notwithstanding these limitations, it is thought that the gratitude training program will contribute to improved quality of life and increased satisfaction with school life among the dental hygienists in training, as the program identified gratitude disposition, self-esteem, and subjective happiness, and helped the students to cultivate a habit of promoting the positive emotional state gained through the program. Maintaining a positive emotional state is thought to nurture the requisite aptitude and sense of duty sought in a dental hygienist, which can ultimately contribute to improved quality of care. The present study's results may prove useful in the efforts to develop a training program designed to promote positive emotions among dental hygienists in training. Finally, more specific measures for expanding gratitude training are needed.

\section{References}

1. Kim NJ, Hwang KS: Dental patient's satisfaction degree factors-concerned with installation of dental clinics. J Korean Acad Dent Technol 22: 129-143, 2000.

2. Steiber SR: How consumers perceive health care quality. Hospitals 62: 84, 1988.

3. Lee HN, Shim HS, Kim GY: Association of quality of dental care service on the level of patient satisfaction. J Korean Soc 
Dent Hyg 11: 383-393, 2011.

4. Ahn ES, Hwang JM, Shin MS: Dental utilization associated factors among elderly. J Dent Hyg Sci 15: 60-66, 2015.

5. Bopp KD: How patients evaluate the quality of ambulatory medical encounters: a marketing perspective. J Health Care Mark 10: 6-15, 1990.

6. Babakus E, Mangold WG: Adapting the SERVQUAL scale to hospital services: an empirical investigation. Health Serv Res 26: 767-786, 1992.

7. Hong HS, Choi YH, Ji YG, Lee SG, Kwon HJ: The effects of the service quality of the dental hygienist on patients' satisfaction and their intentions to revisit and recommend of dental care services. J Korean Acad Oral Health 30: 130-140, 2006.

8. Jeon ES, Choi YJ, Hwang SH: The effect of dental service quality on service value, consumer satisfaction and consumer royalty. J Dent Hyg Sci 13: 246-253, 2013.

9. Jun SH, Jung MH: Relation between the degree of dental service on dental service provider and dental fear. J Korean Soc Dent Hyg 7: 535-551, 2007.

10. Lee KY: Factors affecting the satisfaction level of orthodontic patients with dental service. J Dent Hyg Sci 9: $1-8,2009$.

11. Jung HK, Choi SY, Kwon MY: A study on the medical service MOT control and service performance on the small and medium hospital. J Korea Serv Manag Soc 8: 161-187, 2007.

12. Berk LE: Relationship of caregiver education to child-oriented attitudes, job satisfaction and behavior toward children. Child Care Quart 14: 103-129, 1985.

13. Lee DH: The effects of positive psychological capital of the employees at food service enterprises on organizational citizenship behavior job satisfaction. Int J Tour Manag Sci 31: 385-405, 2016.

14. Yang JH: The effects of thanks journal writing on preservice early childhood teacher's gratitude, self-esteem, and happiness. Korean J Early Child Educ 33: 259-280, 2013.

15. Seligman ME, Csikszentmihalyi M: Positive psychology. An introduction. Am Psychol 55: 5-14, 2000.

16. Seligman MEP: Positive psychology, positive prevention, and positive therapy. In: Snyder CR, Lopez SJ, eds. Handbook of positive psychology. Oxford University Press, New York, pp.3-9, 2002.
17. Emmons RA: Gratitude. In: Peterson C, Seligman MEP, eds. Character strengths and virtues: a handbook and classification. Oxford University Press, New York, pp.553-568, 2004.

18. Watkins PC: Gratitude and subjective well-being. In: Emmons RA, McCullough ME, eds. The psychology of gratitude. Oxford University Press, New York, pp.128-137, 2004.

19. McCullough ME, Emmons RA, Tsang JA: The grateful disposition: a conceptual and empirical topography. J Pers Soc Psychol 82: 112-127, 2002.

20. Rosenberg EL: Levels of analysis and the organization of affect. Rev Gen Psychol 2: 247-270, 1998.

21. Emmons RA, McCullough ME: Counting blessings versus burdens: an experimental investigation of gratitude and subjective well-being in daily life. J Pers Soc Psychol 84: 377-389, 2003.

22. Rosenberg M: Society and the adolescent self-image. Princeton University Press, Princeton, 1965.

23. Hauck PA: Overcoming the rating game: beyond self-love, beyond self-esteem. Westminster/John Knox Press, Louisville, 1991.

24. Park Y, Yang JH: Mothers' and teachers' perceptions on young children's kindergarten adjustment, problem behavior and happiness according to children's peer popularity. J Korea Open Assoc Early Child Educ 17: 73-103, 2012.

25. Kwon SJ, Kim KH, Lee HS: Validation of the Korean version of gratitude questionnaire. Korean J Health Psychol 11: 177-190, 2006.

26. Jeon BJ: Self-esteem: a test of it's measurability. Yonsei Nonchong 11: 107-124, 1974.

27. Lyubomirsky S, Lepper HS: A measure of subjective happiness: preliminary reliability and construct validation. Soc Indic Res 46: 137-155, 1999.

28. Seligman MEP, Kim IJ: Positive psychology: authentic happiness. Mulpure, Anyang, pp.86-88, 2006.

29. Lee JH, Lee $\mathrm{CH}$ : The effect of gratitude training on grateful disposition, life satisfaction, affective well-being, and self-esteem for middle school students. J Korea Acad-Ind Coop Soc 10: 3315-3320, 2009.

30. Sung MH, Kim YH, Ha MJ: The relationships of professional self-concept, professional autonomy and self-esteem to job satisfaction of clinical nurses. J Korean Acad Fundam Nurs 18: 547-555, 2011. 
31. Park SM, Kim AY: The effects of writing a daily log of gratitude on the disposition towards gratefulness and feelings of happiness of elementary school students. Korean J Educ Method Stud 26: 347-369, 2014.

32. Lee HK: Positive emotional characteristics of Koreans.
Psychol Sci 6: 45-60, 1997.

33. Seligman ME, Steen TA, Park N, Peterson C: Positive psychology progress: empirical validation of interventions. Am Psychol 60: 410-421, 2005. 